\title{
Epoxidation of Ethylene by Whole Cell Suspension of Methylosinus trichosporium IMV 3011
}

\author{
Jia-Ying Xin, ${ }^{1,2}$ Ning Xu, ${ }^{1,3}$ Sheng-Fu Ji, ${ }^{4}$ Yan Wang, and Chun-Gu Xia ${ }^{2}$ \\ ${ }^{1}$ Key Laboratory for Food Science \& Engineering, Harbin University of Commerce, Harbin 150076, China \\ ${ }^{2}$ State Key Laboratory for Oxo Synthesis \& Selective Oxidation, Lanzhou Institute of Chemical Physics, Chinese Academy of Sciences, \\ Lanzhou 730000, China \\ ${ }^{3}$ College of Food Science, Northeast Agricultural University, Harbin 150030, China \\ ${ }^{4}$ State Key Laboratory of Chemical Resource Engineering, Beijing University of Chemical Technology, Beijing 100029, China
}

Correspondence should be addressed to Jia-Ying Xin; xinjiayingvip@163.com

Received 17 October 2016; Accepted 4 January 2017; Published 16 February 2017

Academic Editor: Pasquale Longo

Copyright ( 2017 Jia-Ying Xin et al. This is an open access article distributed under the Creative Commons Attribution License, which permits unrestricted use, distribution, and reproduction in any medium, provided the original work is properly cited.

Methane monooxygenase (MMO) has been found in methanotrophic bacteria, which catalyzes the epoxidation of gaseous alkenes to their corresponding epoxides. The whole cell suspension of Methylosinus trichosporium IMV 3011 was used to produce epoxyethane from ethylene. The optimal reaction time and initial ethylene concentration for ethylene epoxidation have been described. The product epoxyethane is not further metabolized and accumulates extracellularly. Thus, exhaustion of reductant and the inhibition of toxic products make it difficult to accumulate epoxyethane continuously. In order to settle these problems, regeneration of cofactor $\mathrm{NADH}$ was performed in batch experiments with methane and methanol. The amount of epoxyethane formed before cosubstrate regeneration was between 0.8 and $1.0 \mathrm{nmol} / 50 \mathrm{mg}$ cells in approximately $8 \mathrm{~h}$. Combining data from 7 batch experiments, the total production of epoxyethane was $2.2 \mathrm{nmol}$. Production of epoxyethane was improved (4.6 nmol) in $10 \%$ gas phase methane since methane acts as an abundant reductant for epoxidation. It was found that the maximum production of epoxyethane $(6.6 \mathrm{nmol})$ occurs with $3 \mathrm{mmol} / \mathrm{L}$ methanol. The passive effect of epoxyethane accumulation on epoxyethane production capacity of Methylosinus trichosporium IMV 3011 in batch experiments was studied. Removal of product was suggested to overcome the inhibition of epoxyethane production.

\section{Introduction}

As the most utilized epoxide, epoxyethane is a useful and important intermediate for industrial chemical production including agricultural chemicals, pharmaceuticals, and polymers and accounts for nearly $40-50 \%$ of the total value of organic chemicals [1]. In addition to application in chemical manufacturing processes, epoxyethane is widely used in processes of food fumigating sterilization, particularly of grains and dried fruits [2]. Direct oxidation of ethylene to epoxyethane with molecular oxygen is a significant synthetic method for both industry and academia. During the last decades, many research works have been focused on epoxidation reactions of ethylene by supported catalysts such as transition metal complexes and metal nanoparticles [3-6].

In contrast with chemical synthetic methods, the biocatalytic reaction appears to be a mild and simple method [7].
One biocatalytic method for producing epoxyethane is using enzymes to insert oxygen across the carbon double bonds of ethylene. Methane monooxygenase (MMO) is such a fascinating enzyme that can efficiently catalyze ethylene to ethylene epoxide with high region specificity and stereoselectivity $[8,9]$. Epoxyethane synthesis by MMO catalysis has significant application potential as it is performed at normal temperature and pressure and causes no pollution.

It is known that the same MMO system catalyzes both ethylene and propene epoxidation reactions. In the past few years, many studies have been focused on MMO catalyzed epoxidation of propene, but with little attention to ethylene. For example, Hou et al. used methane-grown bacteria, which contain the MMO system to oxidize propene to epoxypropane. The optimal conditions for epoxidation were described [10]. Hou performed a gas-solid bioreactor to ensure continuous production and removal of product 
epoxide from the microenvironment of the biocatalyst [11]. Xin et al. chose methane as the electron-donating cosubstrate for propene epoxidation and maximum production of epoxypropane occurred in an atmosphere of $30 \%$ methane [12]. Xin et al. successfully drove epoxypropane synthesis using methanol as the sole carbon source and the electrondonating substrate to regenerate the NADH [13].

In spite of this progress, reaction conditions for biocatalytic ethylene epoxidation and the effect of epoxyethane on MMO catalytic performance have not yet been fully elucidated. Furthermore, for prolonged maintenance of ethylene epoxidation, constant sources of reductant for monooxygenation are critical.

In the present study, we aim at using whole cell suspension of Methylosinus trichosporium IMV 3011 for the biosynthesis of epoxyethane from ethylene. The optimal reaction time and initial concentration of ethylene in epoxidation biosynthesis are described. To sustain epoxidation for a longer time, methane and methanol were selected as substrates for $\mathrm{NADH}$ regeneration. The effect of epoxyethane concentration on epoxyethane production capacity of Methylosinus trichosporium IMV 3011 in batch experiments was studied.

\section{Materials and Methods}

2.1. Organism and Enrichment. Methylosinus trichosporium IMV 3011 was obtained from the Russia Institute of Microbiology and Virology (Kiev, Ukraine). The organism was grown at $30^{\circ} \mathrm{C}$ in a sealed $250 \mathrm{~mL}$ flask containing $60 \mathrm{~mL}$ nitrate mineral salts medium (NMS) with methane and air $(1: 2$, $\mathrm{vol} / \mathrm{vol})$.

Cells were harvested after $96 \mathrm{~h}$ of growth by centrifugation at $8,000 \times \mathrm{g}$ for $15 \mathrm{~min}$ at $4^{\circ} \mathrm{C}$, washed twice with $20 \mathrm{mmol} / \mathrm{L}$ phosphate buffer $(\mathrm{pH} 7.0$ ) containing $5 \mathrm{mmol} / \mathrm{L}$ $\mathrm{MgCl}_{2}$. The final pellets were resuspended in the same buffer to yield a cell density $1.0-3.0 \mathrm{mg}$ dry weight cell $[\mathrm{dwc}] / \mathrm{mL}$ of culture.

2.2. Assay of Epoxyethane Production Capacity. The epoxyethane production capacity of intact cells was determined in a $10 \mathrm{~mL}$ vial (capped with rubber cap) containing $1 \mathrm{~mL}$ cell suspension. The gas phase of the vial was replaced with a gas mixture of ethylene and oxygen (1:1, vol/vol). Reaction mixtures were shaken $(180 \mathrm{rpm})$ at $30^{\circ} \mathrm{C}$ for $30 \mathrm{~min}$. Samples were centrifuged at $8,000 \times \mathrm{g}$ for $15 \mathrm{~min}$ and then cooled down rapidly to $4^{\circ} \mathrm{C}$. A $1 \mu \mathrm{L}$ sample was analyzed immediately by gas chromatography. The concentration of epoxyethane was measured with a gas chromatograph equipped with a capillary column $(\Phi 0.23 \mathrm{~mm} \times 30 \mathrm{~m}$; stationary phase, SE-54) and a flame ionization detector (FID). The temperatures of the injector, column, and detector were maintained at $180^{\circ} \mathrm{C}$, $60^{\circ} \mathrm{C}$, and $180^{\circ} \mathrm{C}$, respectively. Nitrogen was used as a carrier gas at a flow rate of $75 \mathrm{~mL} / \mathrm{min}$. The epoxyethane was identified by retention time comparison and the concentration was estimated by establishing a linear relationship between peak area and concentration. The epoxyethane production capacity of intact cells was expressed as nanomoles of epoxyethane formed per minute per milligram of dry weight of cell.

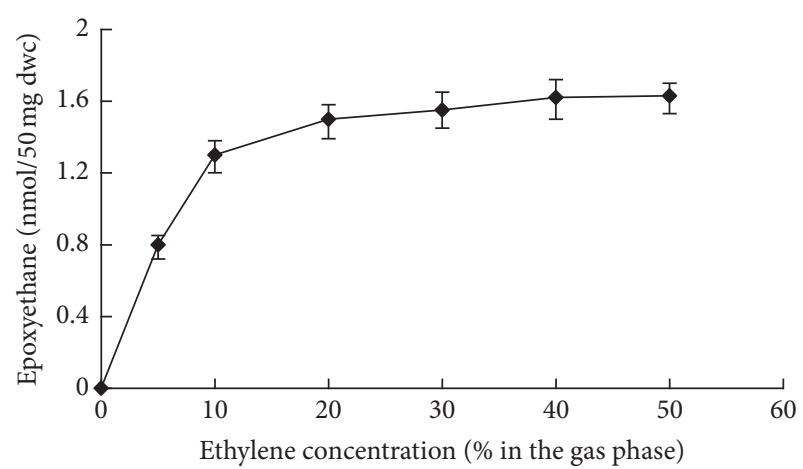

FIGURE 1: The effect of ethylene concentration on the production of epoxyethane by whole cell suspension of Methylosinus trichosporium IMV 3011.

2.3. Batch Experiments. The batch experiments were performed in $100 \mathrm{~mL}$ sealed flasks containing $25 \mathrm{~mL}$ washed cell suspension. The gas phase of the flask was replaced with a gas mixture of ethylene and oxygen (described in the text, $\mathrm{vol} / \mathrm{vol}$ ). The flasks were incubated and shaken at $30^{\circ} \mathrm{C}$ at $180 \mathrm{rpm}$. The epoxyethane concentration was determined at different reaction times. Epoxyethane production was stopped after $24 \mathrm{~h}$. The cells in the flasks were centrifuged and resuspended in $20 \mathrm{mmol} / \mathrm{L}$ phosphate buffer $(\mathrm{pH} \mathrm{7.0)}$ containing $5 \mathrm{mmol} / \mathrm{L} \mathrm{MgCl}_{2}$ (the cell density $1.0-3.0 \mathrm{mg}$ dry weight cell $[\mathrm{dwc}] / \mathrm{mL}$ of culture) and used for the next batch experiment. The above repeating process was continued until the subsequent epoxyethane formation ceased.

2.4. Statistical Analysis. All values are expressed as mean values or mean values \pm standard derivations from three independent experiments and analyses. Statistical significance between different groups was analyzed by one-way analysis of variance (ANOVA) with Duncan's multiple range tests using the SPSS version 13.0 (SPSS Inc., Chicago, IL, USA). Statistical significance was defined at $P<0.05$.

\section{Results and Discussion}

3.1. Relation of Accumulation of Epoxyethane with Initial Concentration of Ethylene. Different initial concentrations of ethylene were used to examine the formation of epoxyethane by whole cell suspension of Methylosinus trichosporium IMV 3011. The oxygen concentration in the gas phase of the flask was maintained at 50\% (v/v). Ethylene concentration was diluted by nitrogen gas. The amount of epoxyethane formed was assayed after $8 \mathrm{~h}$ of reaction. Figure 1 shows that epoxyethane production increased rapidly with increasing ethylene concentration when it is less than $20 \%(880 \mu \mathrm{mol} / \mathrm{L})$ gas phase. The rate of epoxidation reaction appears to be relevant to the solubility of ethylene. Saturation of ethylene in the reaction system is the main reason.

3.2. Time Course of Epoxyethane Production. The time course of epoxyethane production from ethylene by whole cell suspension of Methylosinus trichosporium IMV 3011 is shown in Figure 2. The rate of epoxyethane production was rapidly 


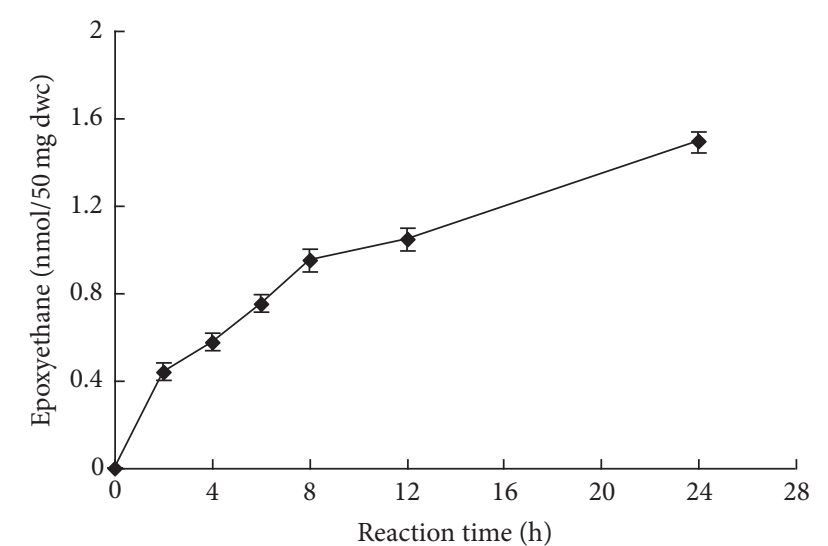

Figure 2: Time course of epoxyethane production catalyzed by whole cell suspension of Methylosinus trichosporium IMV 3011. Initial concentration of ethylene, oxygen, and nitrogen was $20 \%$, $50 \%$, and $30 \%$, respectively.

increased for the first $8 \mathrm{~h}$. The epoxyethane concentration reached a maximum after $12 \mathrm{~h}$ of reaction. The reason for the slow reaction rate between 8 and $12 \mathrm{~h}$ was possible product inhibition or depletion of the endogenous NADH pool. When sodium formate was introduced after the reaction, epoxidation proceeded again, indicating that regeneration of $\mathrm{NADH}$ is a means of restoring reaction progress. Figure 3 shows the NADH regeneration scheme for the production of epoxyethane.

To regenerate nonviable cells of Methylosinus trichosporium IMV 3011, the cell suspension was centrifuged and resuspended in fresh $20 \mathrm{mmol} / \mathrm{L}$ phosphate buffer $(\mathrm{pH}$ 7.0) containing $5 \mathrm{mmol} / \mathrm{L} \mathrm{MgCl}_{2}$ and then regenerated with methane and air $(1: 1, \mathrm{v} / \mathrm{v})$ in a flask. The flask was incubated and shaken at $30^{\circ} \mathrm{C}$ and $180 \mathrm{rpm}$ for $12 \mathrm{~h}$. As mentioned above, methanol, formaldehyde, and formate are methane catabolic intermediates which can regenerate cell MMO activity. However, the initial MMO activity is only partly resumed $(45 \%, 55 \%)$ with formaldehyde $(5 \mathrm{mmol} / \mathrm{L})$ and formate $(10 \mathrm{mmol} / \mathrm{L})$ as the regeneration substrates of nonviable cells. Formaldehyde and formate completely inactivate cells in the second regeneration cycle. The results suggest that formaldehyde and formate are toxic to the Methylosinus trichosporium IMV 3011 cells. In this work, formaldehyde and formate produce a positive effect under the best amendment condition ( $5 \mathrm{mmol} / \mathrm{L}$ formaldehyde, $10 \mathrm{mmol} / \mathrm{L}$ formate). However, the toxic effect is much greater than the positive effect. We thus used a mixture of methane and methanol as the regeneration substrate. The main reason is that a mixture of methane and methanol provides an abundant reductant for ethylene epoxidation with no toxicity.

3.3. Effect of Methane and Methanol on Regeneration of Methylosinus trichosporium IMV 3011. Figure 4 shows the effect of methane concentration on the epoxyethane production capacity of MMO. The whole cell epoxyethane production capacity was enhanced when the methane concentration was less than $10 \%$ of the gas phase. This result suggests that low concentration methane exerts a positive effect on $\mathrm{NADH}$ regeneration. In other words, after the initial oxidation step, methane may be further degraded to regenerate reducing $\mathrm{NADH}$, which can promote further ethylene epoxidation. However, the positive effect was outweighed when the methane concentration was higher than $10 \%$ of the gas phase because of its inhibitory effect. Because oxidation of both ethylene and methane is catalyzed by MMO, the presence of methane may compete with ethylene to bind the MMO active site.

The results in Figure 5 show that 10\% methane initial gas phase exhibits a positive effect on epoxyethane production in batch experiments. The concentration of epoxyethane production decreased as the repetition increased during repetitive batch epoxidation experiments. The main reason is inhibition of epoxyethane production. Moreover, the epoxidation of ethylene can also be performed in the absence of methane by repeating 6 batch cycles, according to Xin et al., approximately due to the utilization of internal energy sources such as poly- $\beta$-hydroxybutyrate [14].

Epoxyethane production by whole cell suspension of Methylosinus trichosporium IMV 3011 in the presence of different concentrations of methanol is shown in Figure 6. The production of epoxyethane from ethylene by cell suspension in the absence of methanol was nearly stopped when the batch reaction was repeated in the 6th batch cycle. The reason for this halt of reaction progress may be the exhaustion of endogenous NADH. As described above, oxidation of methanol catalyzed by dehydrogenases results in the reduction of $\mathrm{NAD}^{+}$to NADH. Thus, methanol exhibits the potential to act as the electron-donating substrate to regenerate $\mathrm{NADH}$ and drive epoxyethane synthesis. Here, $3 \mathrm{mmol} / \mathrm{L}$ methanol addition to ethylene epoxidation reaction led a stable level of the epoxyethane production. However, the formation of epoxyethane in the presence of $1 \mathrm{mmol} / \mathrm{L}$ methanol was still stopped when the batch reaction was repeated for the 6th batch cycle. The reason is that speed of NADH regeneration is lower than speed of NADH consumption.

3.4. Inhibitory Effect of Epoxyethane Production on the Epoxidation of Ethane. A challenging factor in epoxyethane synthesis is that epoxyethane itself has an inhibitory effect on epoxyethane production capacity. To research whether this inhibition is affecting epoxyethane production in this context, the viable cell suspension was treated with epoxyethane. Figure 7 shows the results of the relative epoxyethane production capacity of Methylosinus trichosporium IMV 3011. The epoxyethane production capacity of whole cell suspension is plotted as a function of cells treated over time with epoxyethane. Here, $10 \mathrm{nmol} / \mathrm{L}$ epoxyethane irreversibly inhibits the epoxyethane production capacity totally within $30 \mathrm{~min}$. However, under the same conditions, the epoxyethane production capacity of Methylosinus trichosporium IMV 3011 remains nearly $90 \%$ when cells are treated with $0.1 \mathrm{nmol} / \mathrm{L}$ epoxyethane within $30 \mathrm{~min}$. For comparison, the epoxyethane production capacity of untreated cells is still close to $80 \%$ at $150 \mathrm{~min}$. This result indicates that epoxyethane has an inhibitory effect on epoxyethane production capacity of Methylosinus trichosporium IMV 3011. 


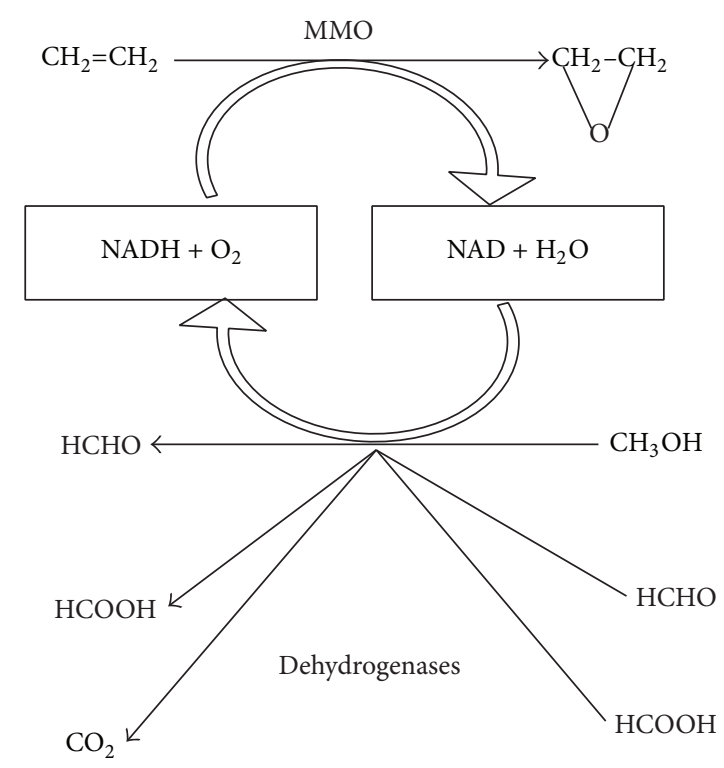

FIGURE 3: NADH regeneration scheme for the production of epoxyethane.
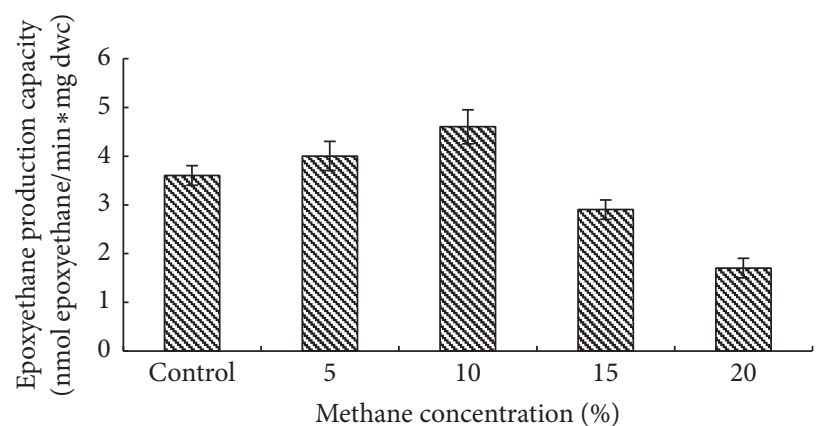

FIGURE 4: Effect of methane on the epoxyethane production capacity. Initial concentrations of ethylene and gas phase oxygen were maintained at $20 \%$ and $50 \%$, respectively. Methane was diluted with nitrogen to produce different concentrations. Whole cell epoxyethane production capacity was assayed after $30 \mathrm{~min}$ of incubation.

It is well known that epoxyethane reacts with water to form ethylene glycol. Khishen made water fully exposed throughout the experiment to the epoxyethane at ordinary temperature [15]. The recovery of the epoxyethane was almost complete after $24 \mathrm{~h}$. Thus, epoxyethane reacted very slowly with water and its reaction with water in the epoxyethane synthesis system was probably so slow as to be neglected.

The inhibitory effect of epoxypropane on MMO activity has been studied previously. Epoxypropane combines with the catalytic site of the enzyme, especially $\mathrm{MMOH}$. The structure of epoxyethane is similar to that of epoxypropane. However, epoxyethane is much more reactive because of the strain of the oxirane ring and the residual positive charge on the carbon atoms. The charge on the carbon atoms gives epoxyethane an electrophilic character. Thus, it is not surprising that epoxyethane is extremely reactive with nucleophilic molecules. Therefore it is thought that epoxyethane

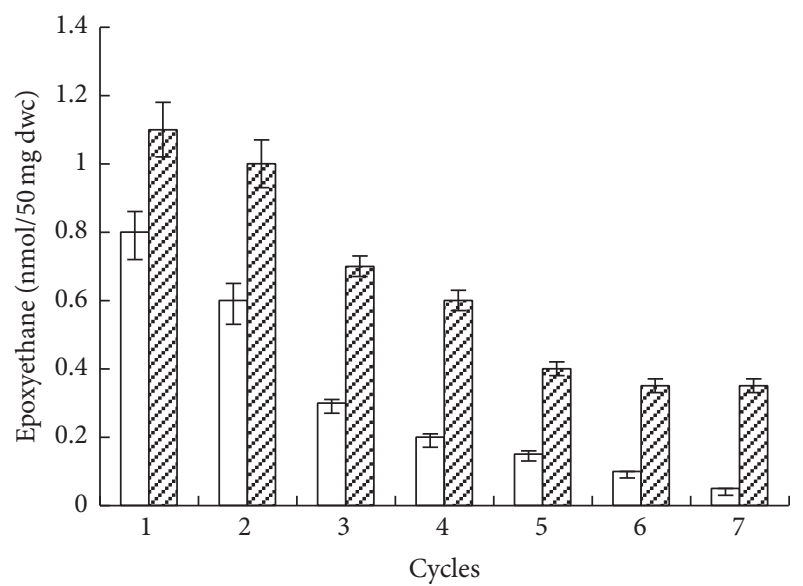

$\square$ Epoxyethane production (I)

E. Epoxyethane production (II)

FIGURE 5: Repetitive batch epoxyethane production with Methylosinus trichosporium IMV 3011. The repetitive batch epoxidation experiments were conducted as described in the text. The above procedure was repeated seven times. (I) Ethylene 20\%, oxygen $50 \%$, and nitrogen $30 \%$. (II) Ethylene 20\%, oxygen 50\%, methane $10 \%$, and nitrogen $20 \%$.

readily reacts with a nucleophilic amino acid residue(s) near the MMO active site. This may be the main reason that epoxyethane has an inhibitory effect on epoxyethane production capacity.

\section{Conclusion}

In recent years, epoxyethane synthesis has received considerable attention because of its possible industrial application [16]. The epoxidation of ethylene by methanotrophic 


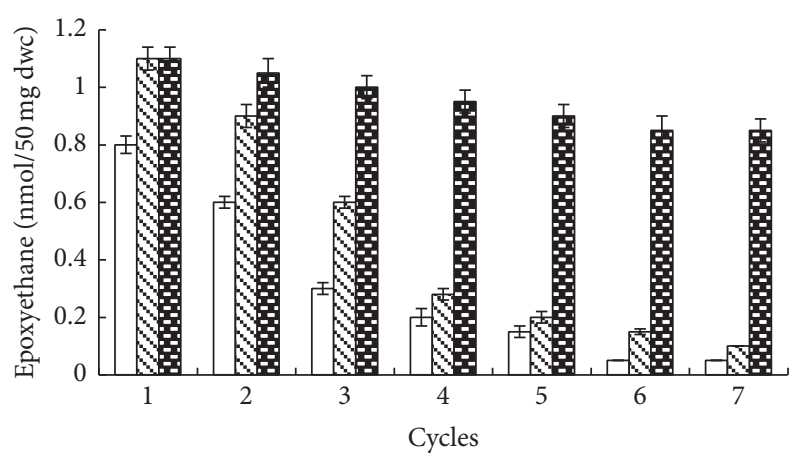

๑ Epoxidation production (I)

๑ Epoxidation production (II)

a Epoxidation production (III)

FIGURE 6: The repetitive batch epoxidation experiments with different methanol concentrations. (I) $0 \mathrm{mmol} / \mathrm{L}$ methanol; (II) $1 \mathrm{mmol} / \mathrm{L}$ methanol; (III) $3 \mathrm{mmol} / \mathrm{L}$ methanol.

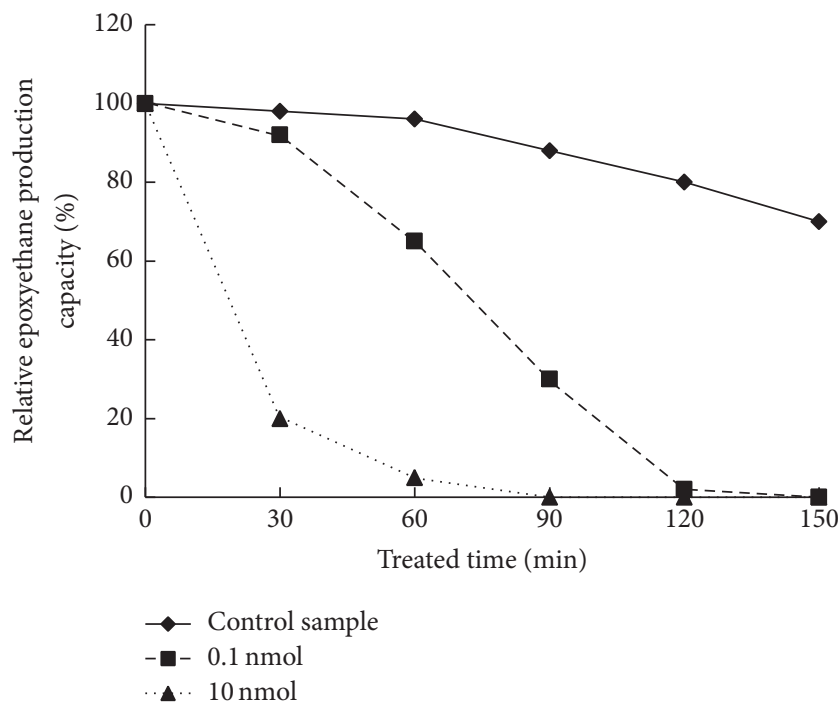

FIGURE 7: Effect of epoxyethane on relative epoxyethane production capacity. Methylosinus trichosporium IMV 3011 cells were treated with epoxyethane ( $10 \mathrm{nmol}, \boldsymbol{\square} 0.1 \mathrm{nmol}$ ) at various times and epoxyethane production capacity is compared with that of the control sample ( $\bullet \mathrm{nmol}$ treated). Treatment condition was the same as epoxyethane synthesis condition.

bacteria in whole cell systems has been reported [8, 1719]. MMO plays a critical role in ethylene epoxidation, which has been found in methanotrophic bacteria. MMO requires a cosubstrate, $\mathrm{NADH}$, for continuous catalysis of the epoxidation of ethylene. In whole cell suspension, when the cosubstrate is depleted, the epoxyethane production stops. Hence, stimulation of epoxidation by methane and its metabolites was investigated in this study. The main reason for the stimulation may be the provision of additional reducing power, or the reduced form of $\mathrm{NAD}^{+}$, for the MMO. Methane and methanol were postulated to be electrondonating cosubstrates since they do not result in toxicity and provide an abundant reductant for ethylene epoxidation.
Batch experiment data shows that addition of $10 \%$ methane or $3 \mathrm{mmol} / \mathrm{L}$ methanol improves production of epoxyethane. A major challenge in the biosynthesis process for the production of epoxyethane is inhibition of production. Results presented here reveal that Methylosinus trichosporium IMV 3011 retains only $90 \%$ epoxyethane production capacity when cells were treated with $0.1 \mathrm{nmol} / \mathrm{L}$ epoxyethane within $30 \mathrm{~min}$.

Based on the present results, it is concluded that a whole cell suspension of Methylosinus trichosporium IMV 3011 represents an efficient biocatalyst for the biosynthesis of epoxyethane. To make the application of Methylosinus trichosporium IMV 3011 on epoxyethane biosynthesis more feasible, uninterrupted reductant for ethylene epoxidation and continuous removal of toxic product are required.

\section{Abbreviations}

MMO: Methane monooxygenase

NADH: Nicotinamide adenine dinucleotide

NMS: Nitrate mineral salts medium

NAD: Nicotinamide adenine dinucleotide

$\mathrm{MMOH}$ : Methane monooxygenase hydroxylase.

\section{Competing Interests}

The authors declare that they have no competing interests.

\section{Acknowledgments}

The authors thank the National Natural Science Foundation of China (21073050, 21573055), the Open Project Program of the State Key Laboratory for Oxo Synthesis and Selective Oxidation, and the State Key Laboratory of Chemical Resource Engineering for support.

\section{References}

[1] M. Ghanta, B. Subramaniam, H.-J. Lee, and D. H. Busch, "Highly selective homogeneous ethylene epoxidation in gas (Ethylene)-expanded liquid: Transport and kinetic studies," AIChE Journal, vol. 59, no. 1, pp. 180-187, 2013.

[2] M. Bononi, G. Quaglia, and F. Tateo, "Identification of ethylene oxide in herbs, spices and other dried vegetables imported into Italy," Food Additives and Contaminants-Part A Chemistry, Analysis, Control, Exposure and Risk Assessment, vol. 31, no. 2, pp. 271-275, 2014.

[3] X. Lu, W.-J. Zhou, H. Wu, A. Liebens, and P. Wu, "Selective synthesis of ethylene oxide through liquid-phase epoxidation of ethylene with titanosilicate $/ \mathrm{H}_{2} \mathrm{O}_{2}$ catalytic systems," Applied Catalysis A: General, vol. 515, pp. 51-59, 2016.

[4] W. Yan, A. Ramanathan, P. D. Patel et al., "Mechanistic insights for enhancing activity and stability of $\mathrm{Nb}$-incorporated silicates for selective ethylene epoxidation," Journal of Catalysis, vol. 336, pp. 75-84, 2016.

[5] Y. Long, B. Yuan, and J. Ma, "Epoxidation of alkenes efficiently catalyzed by Mo salen supported on surface-modified halloysite nanotubes," Chinese Journal of Catalysis, vol. 36, no. 3, pp. 348354, 2015

[6] X. Jing, J. Huang, H. Wang, M. Du, D. Sun, and Q. Li, "Preparation of $\mathrm{Ag} / \alpha-\mathrm{Al}_{2} \mathrm{O}_{3}$ for ethylene epoxidation by an 
impregnation-bioreduction process with Cinnamomum camphora extract," Chemical Engineering Journal, vol. 284, pp. 149157, 2016.

[7] D. A. Carlin, S. J. Bertolani, and J. B. Siegel, "Biocatalytic conversion of ethylene to ethylene oxide using an engineered toluene monooxygenase," Chemical Communications, vol. 51, no. 12, pp. 2283-2285, 2015.

[8] M. Ono and I. Okura, "On the reaction mechanism of alkene epoxidation with Methylosinus trichosporium (OB3b)," Journal of Molecular Catalysis, vol. 61, no. 1, pp. 113-122, 1990.

[9] S. Aono, M. Ono, and I. Okura, "Substrate specificity and stereoselectivity of epoxidation of alkenes with Methylosinus trichosporium (OB3b)," Journal of Molecular Catalysis, vol. 49, no. 3, pp. L65-L67, 1989.

[10] C. T. Hou, R. N. Patel, A. I. Laskin, and N. Barnabe, "Microbial oxidation of gaseous hydrocarbons: oxidation of lower $\mathrm{N}$-alkenes and $\mathrm{N}$-alkanes by resting cell suspensions of various methylotrophic bacteria, and the effect of methane metabolites," FEMS Microbiology Letters, vol. 9, no. 4, pp. 267-270, 1980.

[11] C. T. Hou, "Propylene oxide production from propylene by immobilized whole cells of Methylosinus sp. CRL 31 in a gassolid bioreactor," Applied Microbiology and Biotechnology, vol. 19, no. 1, pp. 1-4, 1984.

[12] J.-Y. Xin, J.-R. Cui, L.-M. Zhu, J.-B. Chen, C.-G. Xia, and S.B. Li, "Epoxypropane biosynthesis by Methylomonas sp. GYJ3: batch and continuous studies," World Journal of Microbiology and Biotechnology, vol. 18, no. 7, pp. 609-614, 2002.

[13] J.-Y. Xin, Y.-X. Zhang, J. Dong et al., "Epoxypropane biosynthesis by whole cell suspension of methanol-growth Methylosinus trichosporium IMV 3011," World Journal of Microbiology and Biotechnology, vol. 26, no. 4, pp. 701-708, 2010.

[14] J. Xin, J. Cui, J. Chen, S. Li, C. Xia, and L. Zhu, "Continuous biocatalytic synthesis of epoxypropane using a biofilm reactor," Process Biochemistry, vol. 38, no. 12, pp. 1739-1746, 2003.

[15] S. A. El Khishen, "Determination of ethylene oxide and methods of its recovery from fumigated substances," Journal of the Science of Food and Agriculture, vol. 1, no. 3, pp. 71-77, 1950.

[16] X. Xiao, X. Jiang, and L. Zhou, "Surface modification of poly ethylene glycol to resist nonspecific adsorption of proteins," Chinese Journal of Analytical Chemistry, vol. 41, no. 3, pp. 445453, 2013.

[17] G. A. Kovalenko and V. D. Sokolovskii, "Epoxidation of propene by microbial cells immobilized on inorganic supports," Biotechnology and Bioengineering, vol. 39, no. 5, pp. 522-528, 1992.

[18] Y. Seki, M. Shimoda, D. Sugimori, and I. Okura, "Epoxidation of allyl compounds with Methylosinus trichosporium (OB3b): stereoselectivity of methane monooxygenase," Journal of Molecular Catalysis, vol. 87, no. 1, pp. L17-L19, 1994.

[19] J. Chen, Y. Xu, J. Xin, S. Li, C. Xia, and J. Cui, "Efficient immobilization of whole cells of Methylomonas sp. strain GYJ3 by sol-gel entrapment," Journal of Molecular Catalysis B: Enzymatic, vol. 30, no. 3-4, pp. 167-172, 2004. 

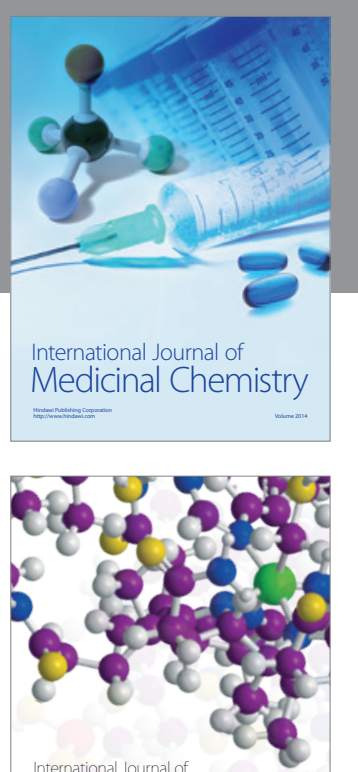

Carbohydrate Chemistry

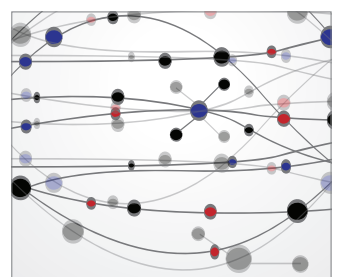

The Scientific World Journal
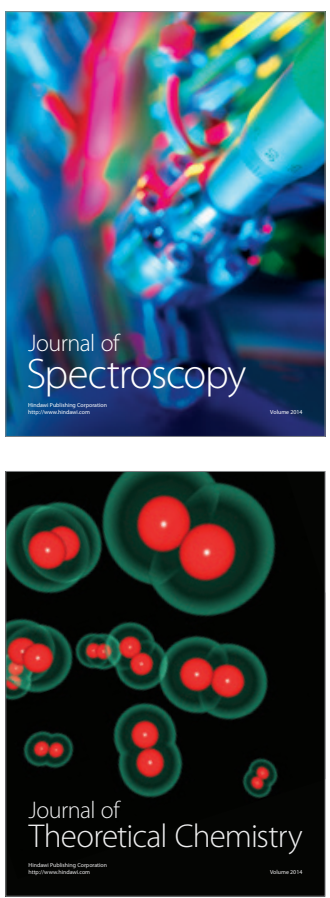
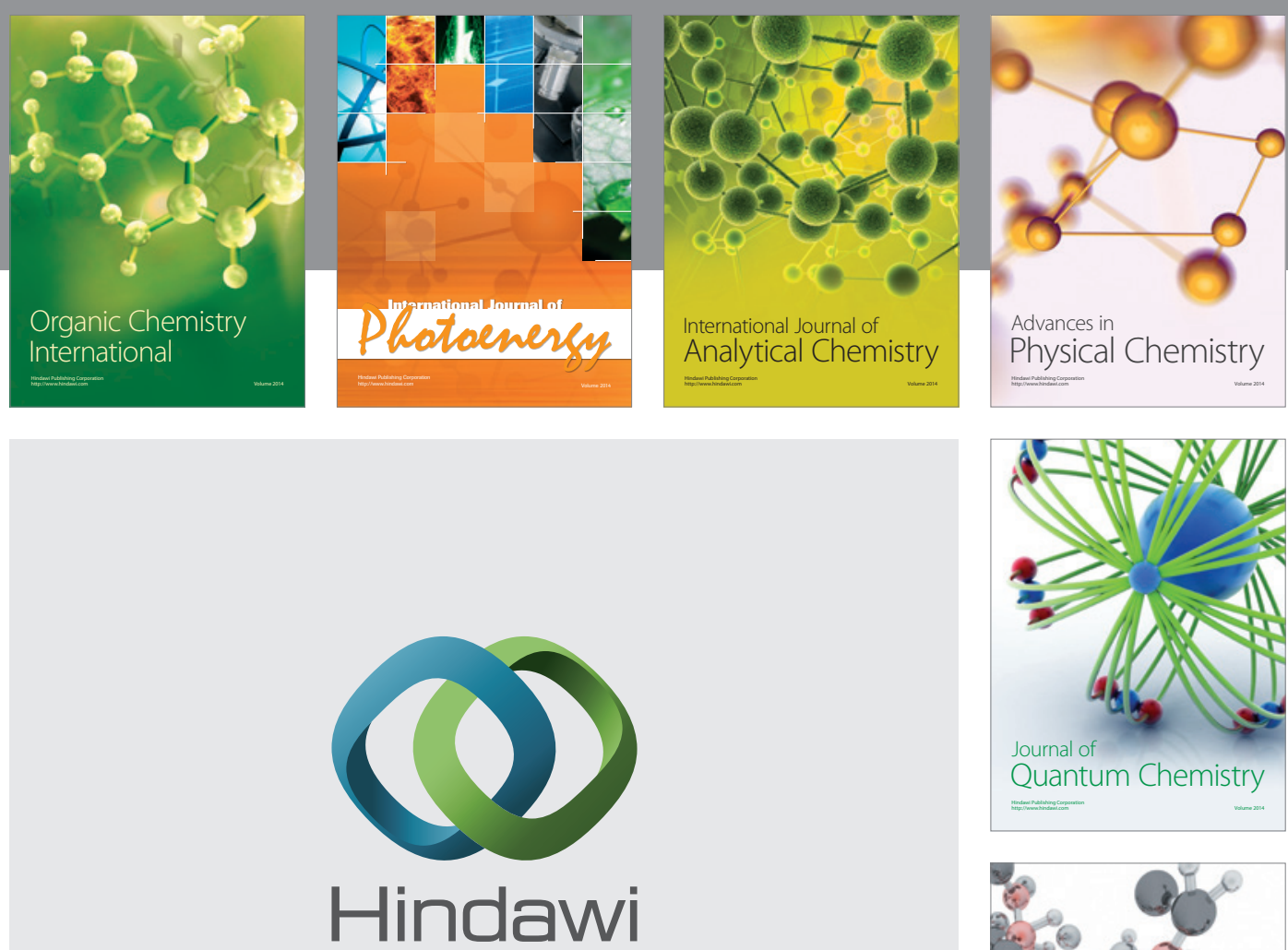

Submit your manuscripts at

https://www.hindawi.com

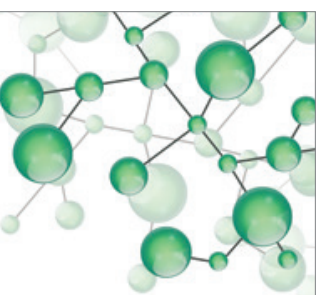

International Journal of

Inorganic Chemistry
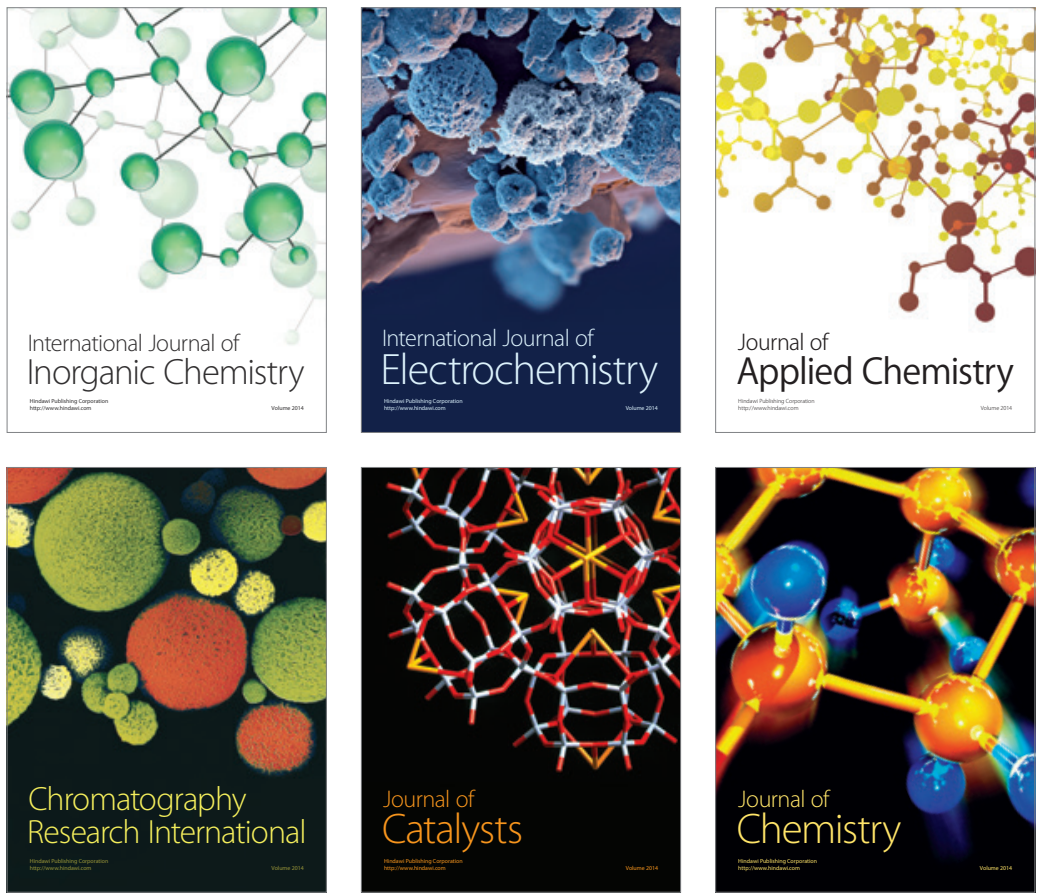

Journal of

Applied Chemistry
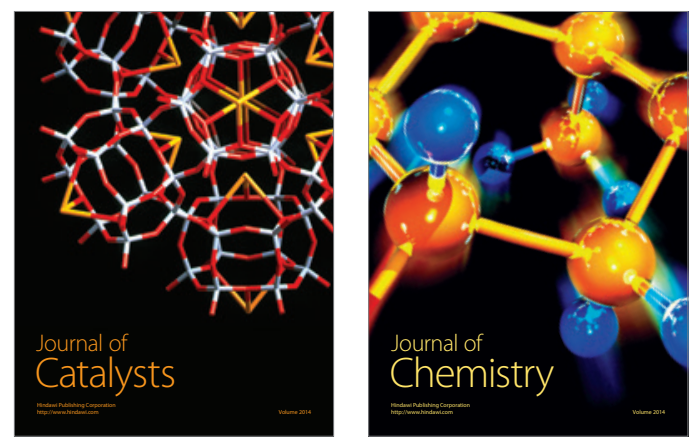
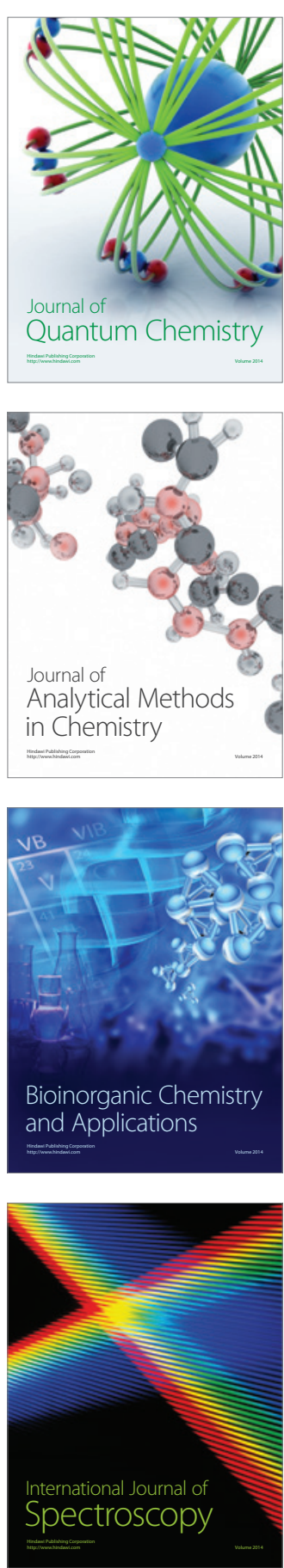